\title{
Surgical Management of Inguinal Hernia In A Kid
}

\author{
Arundhathi $\mathrm{U}^{1}$, Farhan ${ }^{2}$, Ranjith Mohan $\mathrm{M}^{3}$ \\ ${ }^{1}$ Scholar, Bachelor of Veterinary Science and Animal Husbandry, College of Veterinary and Animal Sciences, \\ Mannuthy, Kerala, India \\ ${ }^{2}$ Scholar, Bachelor of Veterinary Science and Animal Husbandry, College of Veterinary and Animal Sciences, \\ Pookode, Kerala, India \\ ${ }^{3}$ Veterinary Surgeon, District Veterinary Centre, Palakkad, Kerala, India
}

\begin{abstract}
Article Info

Volume 7, Issue 4

Protrusion of an abdominal organ through the inguinal canal is called inguinal Page Number: 251-254 hernia. Inguinal hernias are less frequent in ruminants. A two month old Publication Issue :

July-August-2020 female cross bred kid was presented with soft swelling in the left inguinal region. Clinical examination revealed that unilateral reducible inguinal hernia. Herniorraphy resulted in complete reduction of the hernia.
\end{abstract}

\section{Article History}

Accepted : 13 Aug 2020

Published : 19 Aug 2020
Keywords : Inguinal Hernia, Herniorrhaphy, Ligaments, Omentum, IntraAbdominal Pressure

\section{INTRODUCTION}

A hernia is defined as the protrusion of the contents of a body cavity through a normal or abnormal opening in the wall of that cavity either to lie beneath the intact skin or to occupy another adjacent body cavity (Krishnamurthy, 1995). An inguinal hernia is a protrusion of abdominal viscera through the inguinal canal. Potential herniated structures include omentum, urinary bladder, small intestine, large intestine, a portion of the spleen and the uterus with its round and broad ligaments. Female goats were affected than male animals. (Yasin, 2015). Increased intra-abdominal pressure during mounting the males and pregnancy and act of parturition in females are the probable causes of inguinal hernia. When the protruding hernial contents are freely movable and can readily be manipulated back into the cavity, the hernia is termed as reducible. If adhesions form between the contents and the surrounding tissue and the contents are therefore fixed in the abnormal location, the hernia is termed as incarcerated (irreducible). The condition can be diagnosed by palpation of inguinal region, abdominal radiograph and ultrasonography. Inguinal hernia can be managed by surgical correction.

\section{METHODS AND MATERIAL}

A two month old female crossbred kid weighing $7 \mathrm{~kg}$ was presented at District Veterinary Centre, Palakkad. A swelling is noticed on the left inguinal region of the kid. On physical examination hernial ring could be palpated at the left inguinal region through which the hernial mass comes out and the contents were hard in consistency. 


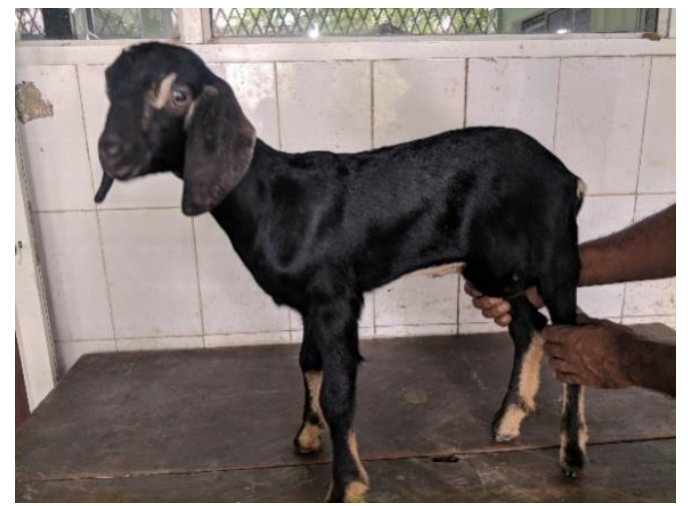

Fig 1. Kid presented with hernial mass on left inguinal region

\section{TREATMENT}

Surgical site was prepared by clipping, shaving and scrubbing with soap and water. A sterile surgical drape was applied around the herniated mass. The skin was scrubbed with $70 \%$ isopropyl alcohol. Animal was administered prophylactic antibiotic therapy with Ceftriaxone1at the dose rate of $20 \mathrm{mg} / \mathrm{kg}$ body weight intravenously and Meloxicam 2 at the dose rate of $0.2 \mathrm{mg} / \mathrm{Kg}$ body weight intramuscularly prior to anaesthesia. Xylazine 3 at the dose rate of $0.1 \mathrm{mg} / \mathrm{kg}$ body weight was given intramuscularly as sedative. Linear infiltration anaesthesia using $1 \mathrm{~mL}$ Lignocaine4 was performed.

Herniorraphy was done by locating the hernial ring. Linear skin incision of about 3 inches was made on cranial to caudal position of herniated mass close to the body using a No. 22 Bard Parker blade and fascia was incised. The contents were intestine and omentum. The contents in the sac were repositioned to abdominal cavity by pushing the contents to inguinal ring manually. The hernial ring was closed by double breasted overlapping suture pattern. The obliquus internus abdominis muscle was sutured in simple interrupted suture pattern using polyglycolic acid 1-0 suture material. The sub cutis was apposed in

\footnotetext{
${ }^{1}$ INTACEF-0.25, Intas Pharmaceuticals ${ }^{2}$ MELONEX, Intas Pharmaceuticals

${ }^{3}$ XYLAXIN, Med-Vet Biolinks Pvt. Ltd

${ }^{4}$ LOX $2 \%$, Neon Laboratories
}

continuous suture pattern using polyglycolic acid 1-0. The wound on skin was apposed in simple interrupted suture pattern using nylon 1-0. Postoperatively, Tincture benzoin was applied over the suture site. Administered $50 \mathrm{ml}$ of dextrose normal saline intravenously and tetanus toxoid. Continued antimicrobial therapy for next 4 days.

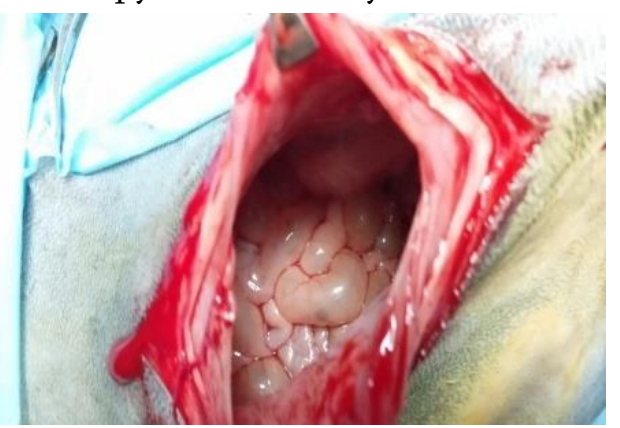

Fig 2. Hernial contents

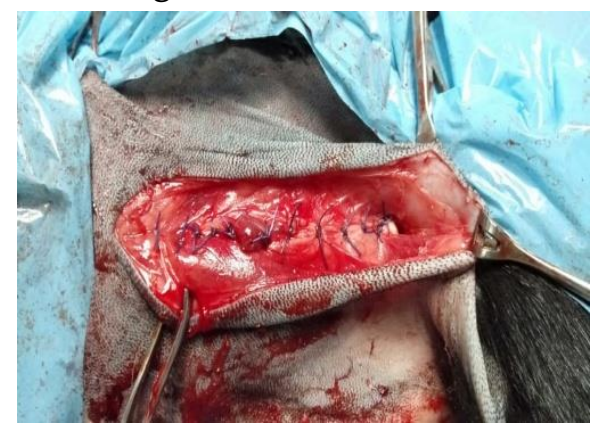

Fig 3. Sutured the muscular layer by simple

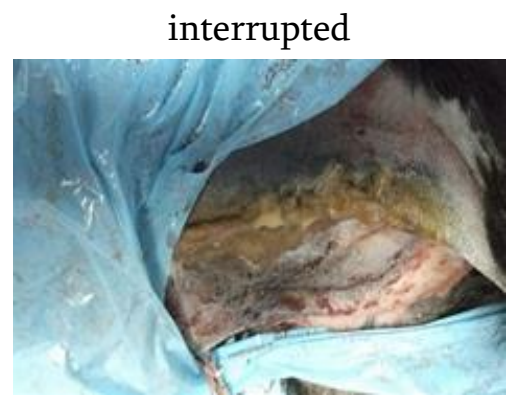

Fig 4 . Sutured the skin by simple interrupted pattern

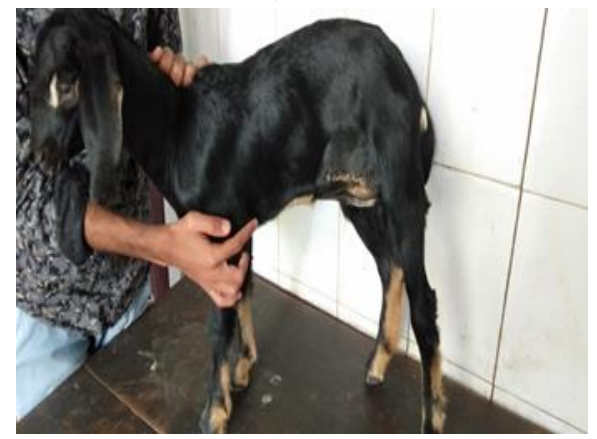

Fig 5. After Surgery 


\section{DISCUSSION}

A hernia is the protrusion or displacement of a part of the abdominal or pelvic content with the intact parietal layer of peritoneum through a natural or pathological opening in the thoracic, abdominal or pelvic wall and in which the skin is intact. The hernial swelling may be rounded, oval or elongated in shape.

Reports on hernias in goats are very rare. (Gohar et al. 1985). Here, in this case, a 2 month old female goat was diagnosed with inguinal hernia. The majority of hernias appeared at the site of natural orifices such as the umbilical and inguinal canal of immature animals, thus suggesting their developmental status (Dennis and Leipold, 1968). Ventral, abdominal and inguinal hernias were observed in adults (Ramadan and Abdin-Bey, 2001). The incidence of abdominal hernias was higher in females and of inguinal hernia was higher in males (Fahd and Ahmed F, 2007). Age and sex of the animal is a predisposing factor in the occurrence of hernia. Repair of large sized hernial ring could be better performed using prosthetic meshes (Youssef et al.1994; Shoukry et al. 1997). The correction is herniorraphy whereas large ring can be corrected by hernioplasty. The size of the hernial swelling was greater in the ventral, abdominal and inguinal hernias of the adult goat. This may be attributed to rupture of the peritoneum and escape of the content to the subcutaneous tissues (Yousef et al., 1994). There is no such complication of peritonitis.

\section{IV.CONCLUSION}

The animal was presented with a history of swelling in the lateral aspect of abdomen. The case was diagnosed as unilateral inguinal hernia. The inguinal hernia was reduced and corrected by performing herniorrhaphy. The animal was then maintained with antibiotics. The animals had an uneventful recovery.

\section{REFERENCES}

[1]. Abdin-Bey, M.R. and Ramadan, R.O. 2001. Retrospective study of hernias in goats. Scientific Journal of King Faisal University (Basic and Applied Sciences).2 (1):77-81.

[2]. Alireza R.J., Seifollah D.N., Musa J.G and Samira, M. 2009. Concurrent bilateral inguinal and umbilical hernia in a bitch: a case report. Veterinarski Archive, 79(5):517-522.

[3]. Al-Sobayil, F.A. and Ahmed, A.F. 2007.Surgical treatment for different forms of hernias in sheep and goats. J.Vet.Sci.vol. 8(2):185- 191.

[4]. Dennis, S.M and Leipold, H.W. 1968. Congenital hernias in sheep. J. Amer. Vet. Med. Ass.152: 999-1003.

[5]. Fahd, A.A. and Ahmed, F.A. 2007. Treatment for different forms of hernias in sheep and goats. J.Vet.Sci. 8(2):185- 191.

[6]. Gohar, H.M., Ramadan, R. O. and Mugal, H. 1987 .Umbilical and Abdominal hernias in ruminants.47:563-575

[7]. Krishnamurthy, D. 1995. Hernia In Thyagi and Jit Singh (ed.), Ruminant surgery (2nd Ed.)C.B.S. Publishers and Distributors, New Delhi, 225p

[8]. Shoukry, M., El-Keiey, M., Hamouda, M and Gadallah. Y (1997). Commercial polyester fabric repair of abdominal hernias and defects. Vet.Rec. 140:606-660

[9]. Singh, K., Bodh, D., Gopinathan, A., Mohsina, A. and Sangeetha, P. (2014). A case of concurrent inguinal hernia and vaginal leiomyoma in a bitch successfully treated surgically. Res. J. vet. pract. 2 (1): $1-4$.

[10].Vijayakumar, M., Arunprasad, A and Pushkinraj, H. (2016)Surgical Management of EnteroHystero-Cystocele in a bitch. IOSR J. Agric.Vet. Sci.9:30-32

[11].Yasin M.I (2015).Clinical observation and surgical management of external hernias 
inruminants

in

DohukGovernorate.Bas.J.Vet.Res.16(1):349-368.

[12].Youssef, H.A., Saleem, S.M., Saleh, A.S., Ali, S.M and Ali, M.A. (1994).ZurTherapieeinigerseltenerHernien. Der PraktischeTierarzt, 1:31-33.

\section{Cite this article as :}

Arundhathi U, Farhan, Ranjith Mohan M, "Surgical Management of Inguinal Hernia in A Kid", International Journal of Scientific Research in Science and Technology (IJSRST), Online ISSN : 2395-602X, Print ISSN : 2395-6011, Volume 7 Issue 4, pp. 251-254, July-August 2020. Available at doi : https://doi.org/10.32628/IJSRST207462

Journal URL : http://ijsrst.com/IJSRST207462 